UNDERGRADUATE RESEARCH IN NATURAL AND CLINICAL SCIENCE AND TECHNOLOGY (URNCST) JOURNAL

Read more URNCST Journal articles and submit your own today at: https://www.urncst.com

\title{
The Dynamic Regulatory Role of miR-132 in Adult Hippocampal Neurogenesis and Neural Stem Cell Development
}

\author{
David Chen, BMSc Student [1]*, Seungmin Lee, BSc Student [2]
}

[1] Schulich School of Medicine and Dentistry, University of Western Ontario, London, Ontario, Canada

[2] Department of Pharmacology and Toxicology, University of Toronto, Toronto, Ontario, Canada

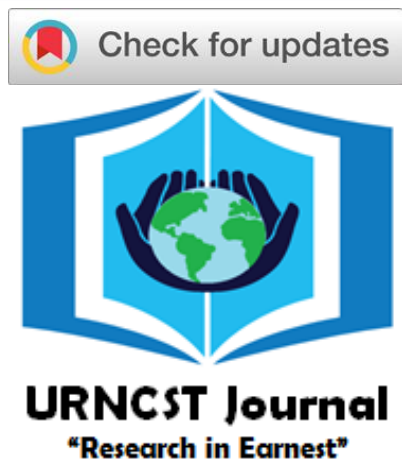

*Corresponding Author: dchen362@uwo.ca

All authors contributed equally.

\begin{abstract}
Introduction: Neurogenesis and neural stem cell development in the adult hippocampus remains an understudied and controversial area of research. These processes are known to be regulated by the dynamic interplay of transcription factors, cell-niche signalling, and recently, microRNAs. microRNA-132 (miR-132) is one example of a miRNA that offers critical insight into neurogenesis and neural stem cell development. The aim of this study was to systematically review the current literature regarding the role of miR-132-mediated post-transcriptional regulation of adult hippocampal neurogenesis (AHN) and neural stem cell (NSC) development.

Methods: The literature search consisted of research articles found in PubMed, MEDLINE, Google Scholar, Cochrane, and Scopus databases using combinations of the Medical Subject Headings (MeSH) keywords "micro-RNA 132", "miR-132", "adult hippocampal neurogenesis", and "neural stem cell development" to filter initial results. The study abstracted data in regards to the modalities of miR-132-mediated post-transcriptional regulation and the histophysiological implications associated with AHN and NSC development.

Results: miR-132 has been implicated in mediating AHN as well as NSC differentiation and integration into the adult hippocampal dentate gyrus. Knockdown and overexpression of micro-RNA 132 in studies have demonstrated that miR-132 acts as a regulator of several downstream pathways and biochemical targets, including p250-GAP, methyl CpG-binding protein 2, AMPA glutamate receptors, and the RAS/MAPK axon signaling pathway. The fine-tuned modulation of neuronal plasticity associated with miR-132 suggests a role in higher level cognition, learning, and neurodegeneration within the context of Alzheimer's disease.

Discussion: The findings that miR-132 serves as a regulator of AHN and NSC development have significant clinical implications, specifically towards better understanding the pathological basis of neurodegenerative disorders as well as the development of novel miRNA-based therapeutics.

Conclusion: The systematic review aggregated key findings on multiple potential biochemical targets and downstream feedback regulation pathways associated with miR-132 expression. Further research is needed to elucidate the mechanism of each pathway and the potential interplay between multiple proteins regulated by miR-132 that are associated with clinical disorders such as Alzheimer's disease.
\end{abstract}

Keywords: adult hippocampal neurogenesis; neural stem cell development; Micro-RNA 132

\section{Introduction}

Over the past few decades, research on the topics of adult neurogenesis (AN) and neural stem cells (NSCs) has made exciting progress. For many years, neurogenesis was believed to be restricted to the embryonic stages of central nervous system development [1]. The paradigm shift began with Altman and Das' landmark studies in the 1960s that first showed the presence of neurogenesis in adult mammalian brains [2,3]. The possibility that nondifferentiated neural stem cells in the adult brain could develop into new neurons in vivo was first hypothesized after two critical studies from Altman's and Das' studies. These studies focused on glial cell proliferation kinetics following brain trauma published in 1962 and the proliferative region of the dentate gyrus in the hippocampus published in 1963 [2,3]. Since the 1990s, AN has been observed and studied in several models, including birds, primates, rodents, as well as humans [4]. Today, neurogenesis is defined as the formation of neurons de novo and is often found in the developing brain [5]. The debated 
UNDERGRADUATE RESEARCH IN NATURAL AND CLINICAL SCIENCE AND TECHNOLOGY (URNCST) JOURNAL Read more URNCST Journal articles and submit your own today at: https://www.urncst.com

frequency, location and functions of neurogenesis has attracted investigations to uncover regulators in the neurogenesis pathway that can attenuate the de novo potential for neurogenesis.

Mammalian AN is primarily restricted to two key areas: the subgranular zone (SGZ) of the hippocampal dentate gyrus (DG) and the subventricular zone (SVZ) of the lateral ventricles, with the former region being the more attractive target for research [1]. The hippocampus is known to be involved with learning and memory and it is hypothesized that adult hippocampal neurogenesis (AHN) plays a role in cognition [1]. Moreover, the generation of new neurons in the hippocampus confers increased neural plasticity and cognitive effects that have yet to be holistically described in vivo [1]. In fact, alterations in AHN have been linked to age-related cognitive decline as well as several neurodegenerative diseases such as Alzheimer's Disease, Parkinson's Disease, mood disorders, and epilepsy [6].

AHN is a complicated process that is regulated by the dynamic interplay between several factors, including transcription factors and cell-niche signalling [7]. Within the last few years, an emergent area of research has been the role of microRNAs (miRNAs) in the regulation of neurogenesis. miRNAs are composed of small noncoding RNA molecules of approximately 22 nucleotides in length [8]. They are expressed in a tissue-specific and tightly regulated manner and function to regulate gene expression at the post-transcriptional level through several methods, such as targeted degradation and by inhibiting translation of mRNA molecules [8]. While research into the role of miRNAs as post-transcriptional regulators of neural stem cells is still in its infancy, it offers an exciting perspective as a critical post-transcriptional mediator of neuronal stem cell self-renewal and fate determination that can serve as a component of cell replacement therapies.

Among these many miRNAs, miR-132 is one that has been extensively studied in the past, specifically regarding its role in mature neurons as a regulator of synaptic plasticity, neurite outgrowth and neuronal morphogenesis. The mature microRNA-132 sequence produced after posttranscriptional modification of precursor microRNA is conserved between mice, rats and humans which brings a degree of transitivity when using mice and rats as mammalian models. However, its role in NSCs is not as clear. miR-132 dysfunction has been implicated in polyglutamine diseases including Huntington's disease, spinobulbar muscular atrophy, dentatorubral-pallidoluysian atrophy and six spinocerebellar ataxias, as well as several neuropathologies such as multiple sclerosis, epilepsy, and severe mood disorders. [6, 8] Specifically in the context of Alzheimer's disease (AD), miR-132 has been found to be consistently downregulated in the brains of these patients, making it an attractive target for research $[9,10]$. Studies continue to better understand the regulatory pathways involved in miR-132 expression and its role in NSCs and
AHN. This review aims to provide a summary of the existing literature surrounding miR-132, emphasizing its role in NSCsas a post-transcriptional regulator of adult hippocampal neurogenesis (AHN) as well as commenting on the recent progress towards its clinical applications for Alzheimer's Disease (AD).

\section{Methods}

The aim of this study was to systematically review the current literature about the role of miR-132 in neural stem cells (NSCs) as a post-transcriptional regulator of adult hippocampal neurogenesis and neural stem cell development. A four-stage approach was employed to further refine selection criteria and to assess credibility of articles.

Stage 1 of the review methodology covered peerreviewed studies documented in English. Randomized control trials, cohort, longitudinal studies, and systematic meta-analyses were evaluated. The literature search consisted of research articles found in PubMed, MEDLINE, Google Scholar, Cochrane, and Scopus databases using combinations of the Medical Subject Headings (MeSH) keywords "micro-RNA 132”, “miR-132”, “adult hippocampal neurogenesis" to filter initial results. Stage 2 of the review methodology employed a utilitarian approach to refine the selection criteria of research articles included in the review. This approach sampled articles published within the last 20 years in peer-reviewed journals to ensure credibility and relevance. Stage 3 of the review methodology abstracted data in regards to the modalities of miR-132 post-transcriptional regulation and the physiological implications associated with adult hippocampal neurogenesis. Stage 4 of the review methodology synthesized abstracted data into five key topics: neurogenesis and NSC differentiation in the hippocampal dentate gyrus (DG), dendritic growth and arborization of new neurons, neuronal plasticity and implications to Alzheimer's Disease. Relationships within and between studies were scrutinized to provide a holistic review and limit sampling bias.

\section{Results}

miR-132 is required for neurogenesis in the adult hippocampal DG

Over the past few years, several studies have implicated the importance of miR-132 in promoting neurogenesis in the adult hippocampal dentate gyrus (DG). Salta et. al. have conducted several comprehensive studies on miR-132 and its role in AHN, demonstrating that miR132 is required for neurogenesis to occur in the $\mathrm{DG}$ in vivo [11]. Exercise is a well-known factor that induces AHN and the authors were interested in whether miR-132 is both necessary and sufficient for this process to occur. Exercisemediated AHN was observed in both wild type C57BL/6 mice as well as those that received an intracerebroventricular (ICV) injection of a scrambled 
UNDERGRADUATE RESEARCH IN NATURAL AND CLINICAL SCIENCE AND TECHNOLOGY (URNCST) JOURNAL Read more URNCST Journal articles and submit your own today at: https://www.urncst.com

siRNA control; however, this was abrogated in mice injected with an antisense oligonucleotide against miR-132 [11]. Similarly, transfection of AD mouse models with synthetic miR-132 mimics restored levels of AHN and cognition [11]. To understand miR-132's molecular network, this experiment was followed-up with gene set enrichment analyses and semi-quantitative real-time PCR validation. 5 mRNAs (DOCK1, EPHB3, BTG2, CAMK1 and $R A C 1$ ), all of which have known roles in neuronal differentiation and function, were identified to be downregulated and hypothesized to be effectors of miR-132 [11].

miR-132 promotes NSC differentiation in the adult hippocampal DG

miR-132 also appears to play a critical role in promoting NSC differentiation in the DG. Jia et al. reported that miR-132 overexpression enhanced NSC differentiation in both in vitro and in vivo models. Notably, in vivo, adult male Sprague-Dawley rats injected with an adenoassociated virus (AAV) vector into the dorsal and ventral DG to selectively overexpress miR-132 in the NSCs demonstrated enhanced differentiation [12]. Other studies, such as one conducted by Chen et al., have suggested that miR-132 promotes glial cell differentiation but negatively regulates NSC self-renewal and neuronal differentiation [13]. Glial cells, which play a supplementary role by providing support and protection for neurons, provide an alternative perspective in how miR-132 can regulate AHN. It is suggested miR-132-mediated glial cell differentiation is facilitated via decreased expression of methyl-CpGbinding protein 2, a well-known transcription repressor [14]. Thus, while it is well understood that miR-132 probably plays a crucial role in the process of NSC differentiation, the exact molecular mechanisms by which miR-132 mediates this process is still under investigation.

$\underline{\text { miR-132 regulates dendritic growth and arborization of }}$ newborn neurons in the adult hippocampus

The expression of miRNA-132 has been implicated in the knockdown of several key signalling pathways that positively regulate adult hippocampal neurogenesis and dendritic growth of newborn neurons. Luikart et al. assessed the effects of miR-132 knockdown on newborn neuron dendrites using a fluorescently tagged, retroviral miR-132 sponge in adult mice and determined that the dendritic spine density decreased $21 \%$ in miR-132 knockdown cells $(1.36 \pm 0.06$ spines $/ \mu \mathrm{m}$ in control, $1.07 \pm 0.09$ spines $/ \mu \mathrm{m}$ in $\mathrm{miR}-132$ expressing mice neurons, respectively) [15]. The positive regulatory role of miR-132 in neuronal morphogenesis was further confirmed in an in vivo study in mice by Magill et al., which reported a dramatic decrease in spine density, dendrite length and arborization upon targeted retroviral deletion of the miR132 locus [16]. The Magill et al. study also identifies p250GAP and methyl CpG-binding protein 2 as potential targets that mediate miR-132 effects on dendritic outgrowth in neurons [16].

miR-132 is associated with downstream cAMP response element binding (CREB)-mediated signalling required for normal neuronal morphogenesis and proliferation of newborn neurons in the adult hippocampus of mice [17]. Ablation of miR-132 can lead to downstream effects due to CREB's role as a transcription factor and ultimately impair arborization of adult hippocampal neurons [17]. In addition, microRNA-132 was reported to target methyl $\mathrm{CpG}$ binding protein 2 (MeCP2), a key protein associated with silencing gene transcription and found within constitutive heterochromatin that plays a role in regulation of neuronal maturation, synaptogenesis as well as dendritic development [18]. miR-132 knockdown increased MeCP2 expression and brain-derived neurotrophic factor (BDNF) levels in rat neurons in vitro and was proposed by Klein et al. as a method of homeostatic control of MeCP2 expression [18]. The two studies of miR-132 knockdown cells by Luikart et al. and Magill et al. demonstrate that miR-132 regulates the transcription of key targets necessary for dendritic growth, arborization of newborn neurons and de novo dendritic spine formation in the adult hippocampus.

Kawashima et al. described the influence of microRNA-132 overexpression on marked upregulation of glutamate receptors GluA1, GluN2A and GluN2B in cultured rat cortical neurons [19]. The results of Kawashima et al. support the finding that microRNA-132 expression has a positive correlation with the increase in proliferation of hippocampal neural progenitor cells associated with AMPA receptor activation [19]. Overall, miRNA-132 has been shown to be positively correlated with dendritic growth, arborization of newborn neurons and dendritic spine formation. miRNA-132 can regulate the synaptic circuitry and growth of newborn neurons in the adult hippocampus through multiple downstream biochemical targets such as the CREB signalling pathway, $\mathrm{MeCP} 2$ in heterochromatin and AMPA-associated neural proliferation, although the extent of each mechanism remains to be identified.

Modulation of neuronal plasticity associated with miR-132

Neuronal plasticity is an important feature of the brain that allows it to continuously adapt in response to changing stimuli. There is strong evidence that miR-132 is involved in mediating the synthesis of new hippocampal neurons that extends neonate developmental plasticity into adulthood [20]. Esposito et al. discovered that newborn neurons in the adult dentate gyrus of the mice models recapitulate neonate neuronal developmental pathways such as differentiation, proliferation and functional integration into the synaptic circuitry and suggests a model where additional checkpoints for neuronal connectivity can maintain a level of hippocampal plasticity necessary for higher-level learning [20]. Moreover, the understanding of the role of 
UNDERGRADUATE RESEARCH IN NATURAL AND CLINICAL SCIENCE AND TECHNOLOGY (URNCST) JOURNAL Read more URNCST Journal articles and submit your own today at: https://www.urncst.com

miR-132 in mature hippocampal neurons to modulate the synaptic phenotype and local biochemical pathways can lead to a deeper understanding of the hippocampal environmental factors conducive to AHN [15]. Impey et al. demonstrated that microRNA-132 expression activates Rac1-Pal actin remodelling pathways involved in activitydependent dendritic spine plasticity in rat hippocampal neurons from postnatal weeks 2 to 4 [21]. Furthermore, the study by Hancock et al. observed the presence of both miR132 and the Ras1 protein that regulate the RAS/MAPK signaling pathway in axons and suggested a model where miR-132 regulated translation of Rasa1 locally within the axon [22]. These findings supported the idea that miR-132 regulates protein synthesis through moderation of target mRNA translation that ultimately affects signal transduction pathways associated with long-term neuronal plasticity.

Lambert et al. reported that in mice, hippocampal neurons overexpressing miR-132 showed decreased rate of synaptic depression (10th Stimulus: EGFP Control $0.34 \pm 0.04, \mathrm{n}=33 ;$ miR-132 $0.69 \pm 0.07, \mathrm{n}=21 ; \mathrm{P}<0.0005)$ compared to controls at all time points and increased paired-pulse ratio (EGFP Control 0.77 $\pm 0.04, n=34$; miR132 $1.06 \pm 0.06, \quad \mathrm{n}=21 ; \mathrm{P}<0.0005)$, a measure of activity-dependent signal transduction associated with synaptic plasticity, following a train of 40 stimuli delivered at $20 \mathrm{~Hz}$ and normalization [23]. This suggests that activitydependent miR-132 expression selectively affects shortterm plasticity of adult hippocampal neurons in mice, which uniquely compares to the previous studies that focused on long-term neuronal plasticity [23]. However, further research is needed to elucidate the candidate mRNA targets of miRNA-132 that can mediate neuronal plasticity. Together, these studies demonstrate that the critical role of microRNA-132 in modulating synaptic plasticity is highly regulated based on its degree of expression as a mediator between positive or negative feedback of downstream pathways.

Clinical implications of miR-132, specifically in the context of Alzheimer's Disease

miR-132 has profound clinical implications as it is one of the few miRNAs to be consistently implicated with Alzheimer's Disease. Several studies have conducted miRNA profiling on the brains of Alzheimer's Disease (AD) patients, and they have all reported significant miR132 downregulation [9,10]. Follow-up studies have associated miR-132 deficiency with the two key pathologic markers of $\mathrm{AD}$, aggregated amyloid $\beta(\mathrm{A} \beta)$ plaques and neurofibrillary tangles of hyperphosphorylated tau, both of which are implicated with impaired AHN [24,25]. As such, understanding the mechanisms by which miR-132 dysfunction impairs AHN and contributes to AD pathology may provide insight into novel therapeutic approaches.

Amyloid $\beta(\mathrm{A} \beta)$, a 39-43 amino acid peptide, is found in high levels in the brains of AD patients [26,27]. They aggregate to form plaques, which are implicated with neurodegeneration [26,27]. Extracellularly, they disrupt cell membrane function and intracellularly, they elicit cytotoxic signals, including binding to and disrupting Tau [26,27]. Overall, $\mathrm{A} \beta$ deregulates neurogenesis, which is one contributing factor to disease progression [28]. HernandezRapp et al. used triple transgenic AD mice to show that miR-132 deletion leads to enhanced $\mathrm{A} \beta$ plaque formation and is associated with the upregulation of Tau, Mapk and Sirt1, all proteins with known roles in regulating $\mathrm{A} \beta$ metabolism [29]. Bioinformatics using GeneMANIA was used to identify the associated proteins within the miR-132 network and the association was confirmed through Western blot analysis [29].

Neurofibrillary tangles form due to the hyperphosphorylation of Tau, causing Tau to detach from microtubules and form large intracellular lumps [30]. Neurofibrillary tangles contribute to impaired AHN by interfering with the neuron's transport system and negatively affecting synaptic communication and signal transduction [30,31]. Smith et. al. focused their efforts on understanding the impacts of miR-132 downregulation on tau metabolism in vivo. They identified miR-132 as a direct regulator of Tau by targeting its mRNA, and miR-132 knockout studies in mice demonstrated significantly increased Tau expression, phosphorylation and aggregation [29]. Salta et. al. proposed that miR-132 deficiency promotes both amyloid $\beta$ plaque and neurofibrillary tangle formation via upregulation of inositol 1,4,5-trisphosphate 3kinase B (ITPKB), which in turn leads to elevated levels of ERK1/2 and BACE1 activity as well as TAU phosphorylation [30]. While these results were observed in AD mouse models, they were confirmed in three distinct human $\mathrm{AD}$ patient cohorts, highlighting the relevance of the findings to human populations.

Interestingly, miR-132 also offers promise as a potential therapeutic agent. Several studies have shown that transfection of miR-132 in $\mathrm{AD}$ mice has been shown to biochemically decrease overall levels of hyperphosphorylated Tau, reduce levels of neuronal death and offer protection against the toxic effects of $\mathrm{A} \beta$ plaques as well as improve behavioural outcomes in cognition and memory [31]. While further studies in animal models are still required, miR-132 has shown to be clinically significant towards the development of new treatments for AD patients.

\section{Discussion}

miRNAs as post-transcriptional regulators of neurogenesis have been an emergent area of research within the past few years. Specifically, miRNA dysregulation has been implicated with age-related cognitive decline as well as several neurodegenerative diseases such as Alzheimer's Disease, Parkinson's Disease, mood disorders, and epilepsy, making this a clinically relevant area of research [6]. However, the role of specific miRNAs for each of these 
UNDERGRADUATE RESEARCH IN NATURAL AND CLINICAL SCIENCE AND TECHNOLOGY (URNCST) JOURNAL Read more URNCST Journal articles and submit your own today at: https://www.urncst.com

conditions and their utility as potential components of cell replacement therapies remains to be further investigated.

This literature review focuses on miR-132, specifically on its role in AHN and NSC development as well as its clinical relevance to Alzheimer's Disease. miR-132 modulates neuronal processes through post-transcriptional regulation that affect hippocampal neurons across successive stages of development and lead to both positive and negative implications in differentiation, dendritic growth, synaptic plasticity, and neurological diseases [1]. Studies have shown that miR-132 is necessary for AHN in the DG and that overexpression of miR-132 both in vitro and in vivo enhances NSC differentiation [11,12]. Further studies have explored the exact molecular mechanisms mediated by miR-132. We found that the expression of miRNA-132 regulates Rac1-Pal actin remodelling pathways associated with activity-dependent dendritic spine plasticity and targets p250GAP protein by translational block and downstream CREB signalling to increase neuronal morphogenesis $[17,21]$. The modulation of signal transduction by miRNA-132 is associated with neurodegenerative diseases such as Alzheimer's Disease, where the deletion of miR-132 expression enhances amyloid $\beta$ plaque formation and negatively correlates with the upregulation of Tau protein expression and aggregation implicated in Alzheimer's [26-30]. In addition, MAPK signalling cascades and Sirt1 activity, both of which are involved in regulating $\mathrm{A} \beta$ metabolism, were also found to be negatively regulated by post-transcription regulators such as miR-132 [31]. The association of miRNA-132 with the Tau, MAPK and Sirt1 pathways is significant cause for further research on the physiological and pathological consequences of their expression.

\section{Conclusions}

Our systematic literature review discussed the role of miR-132 in mediating AHN and promoting NSC development. The clinical significance of these findings was then discussed in the context of Alzheimer's Disease. Evidence suggests that miR-132 serves as a posttranscriptional regulator of AHN as well as a key regulator NSC differentiation, dendritic growth, arborization of new neurons and neuronal plasticity. In addition, several downstream pathways for miR-132 were identified regarding various aspects of AHN and NSC development. These results, coupled with the potential for miRNAs to serve as components of cell replacement therapies, provides great hope towards the development of novel miRNA-based therapeutics. miR-132 already shows great promise for the treatment of Alzheimer's Disease and these findings have the potential to be extended towards developing breakthrough therapies for a range of neurodegenerative disorders.

\section{List of Abbreviations Used}

$\mathrm{A} \beta$ : amyloid $\beta$

AD: Alzheimer's Disease

AN: adult neurogenesis

AHN: adult hippocampal neurogenesis

BDNF: brain derived neurotrophic factor

CREB: cAMP response element binding

DG: dentate gyrus

ICV: intracerebroventricular

ITPKB: inositol 1,4,5-trisphosphate 3-kinase B

MeCP2: methyl CpG binding protein 2

MeSH: Medical Subject Headings

MiRNA: Micro-RNA

NSC: neural stem cell

SVZ: subventricular zone

\section{Conflicts of Interest}

The authors declare that they have no conflict of interests.

\section{Ethics Approval and/or Participant Consent}

Article did not require ethics approval or participant consent since the review only included secondary, published sources.

\section{Authors' Contributions}

DC: Significant contribution to collection of articles for review, data interpretation, drafted the manuscript and gave final approval of the version to be published.

SL: Significant contribution to collection of articles for review, data interpretation, drafted the manuscript and gave final approval of the version to be published.

\section{Acknowledgements}

Amy Yeung: Mentorship and significant contribution to the conception and direction of the work.

\section{Funding}

This study was not funded.

\section{References}

[1] Depression [Internet]. Who.int. 2020 [cited 14 November 2020]. Available from: https://www.who.int/ news-room/fact-sheets/detail/depression

[2] Depression Definition and DSM-5 Diagnostic Criteria [Internet]. Psycom.net - Mental Health Treatment Resource Since 1996. 2020 [cited 14 November 2020]. Available from: https://www.psycom.net/depressiondefinition-dsm-5-diagnostic-criteria/

[3] Depression - Mental Health - Publications - Public Information - MOHLTC [Internet]. 2020 [cited 14 November 2020]. Available from: http://www.health.gov.on.ca/en/public/publications/me ntal/depression.aspx

[4] Bowman M, Daws L. Targeting Serotonin Transporters in the Treatment of Juvenile and Adolescent Depression. 
UNDERGRADUATE RESEARCH IN NATURAL AND CLINICAL SCIENCE AND TECHNOLOGY (URNCST) JOURNAL

Read more URNCST Journal articles and submit your own today at: https://www.urncst.com

Frontiers in Neuroscience. 2019 Feb 27;13(156):1-14. https://doi.org/10.3389/fnins.2019.00156

[5] Felger, J. and Lotrich, F., 2013. Inflammatory cytokines in depression: Neurobiological mechanisms and therapeutic implications. Neuroscience. 2013 May 3;246:199-229. https://doi.org/10.1016/j.neuroscience .2013 .04 .060

[6] Scheffer D, Latini A. Exercise-induced immune system response: Anti-inflammatory status on peripheral and central organs. Biochimica et Biophysica Acta (BBA) Molecular Basis of Disease. 2020 Apr 29;1866(10):115. https://doi.org/10.1016/j.bbadis.2020.165823

[7] Maeng S, Hong H. Inflammation as the Potential Basis in Depression. International Neurourology Journal. 2019 Nov 30;23(Suppl 2):S63-71. https://doi.org/ 10.5213/inj.1938226.113

[8] Inazu M, Takeda H, Ikoshi H, Sugisawa M, Uchida Y, Matsumiya T. Pharmacological characterization and visualization of the glial serotonin transporter. Neurochemistry International. 2001 Jul;39(1):39-49. http://doi.org/10.1016/s0197-0186(01)00010-9

[9] Rheumatoid Arthritis : Anti-TNF Therapy for the Treatment of RA [Internet]. Johns Hopkins Arthritis Center. 2020 [cited 14 November 2020]. Available from: $\quad$ https://www.hopkinsarthritis.org/arthritisinfo/rheumatoid-arthritis/ra-treatment/anti-tnf-therapyfor-ral

[10] Corrêa S, Eales K. The Role of p38 MAPK and Its Substrates in Neuronal Plasticity and Neurodegenerative Disease. Journal of Signal Transduction. 2012;2012:1-12. S, Eales K. The Role of p38 MAPK and Its Substrates in Neuronal Plasticity and Neurodegenerative Disease. Journal of Signal Transduction. 2012;2012:1-12.

[11] Sabio G, Davis R. TNF and MAP kinase signalling pathways. Seminars in Immunology. 2014;26(3):237245. https://doi.org/10.1016/j.smim.2014.02.009

[12] Xiao Y, Yan W, Cao Y, Yan J, Cai W. P38 MAPK Pharmacological Inhibitor SB203580 Alleviates Total Parenteral Nutrition-Induced Loss of Intestinal Barrier Function but Promotes Hepatocyte Lipoapoptosis. Cellular Phy siology and Biochemistry. 2017;41(2):623634. https://doi.org/10.1159/000457933

[13] MAPKAPK2 Gene - GeneCards | MAPK2 Protein | MAPK2 Antibody [Internet]. Genecards.org. 2020 [cited 14 November 2020]. Available from: https://www.genecards.org/cgi-bin/carddisp.pl?gene $=$ MAPKAPK2

[14] Moon M, Cho B, Lee Y, Choi S, Lim S, Park K et al. The effects of chronic exercise on the inflammatory cytokines interleukin- 6 and tumor necrosis factor- $\alpha$ are different with age. Applied Physiology, Nutrition, and Metabolism. 2012 Aug;37(4):631-636. https://doi.org/ 10.1139/h2012-039

[15] Malynn S, Campos-Torres A, Moynagh P, Haase J. The Pro-inflammatory Cytokine TNF- $\alpha$ Regulates the
Activity and Expression of the Serotonin Transporter (SERT) in Astrocytes. Neurochemical Research. 2013 Apr;38(4):694-704. https://doi.org/10.1007/s11064012-0967-y

[16] Triantafillidis, J., 2005. Favorable response to subcutaneous administration of infliximab in rats with experimental colitis. World Journal of Gastroenterology. 2005 Nov 21;11(43):6843-6847.https://doi.org/10.3748 /wjg.v11.i43.6843

[17]Zhu C, Blakely R, Hewlett W. The Proinflammatory Cytokines Interleukin-1beta and Tumor Necrosis Factor-Alpha Activate Serotonin Transporters. Neuropsychopharmacology. 2006 Feb 1;31(10):21212131. https://doi.org/10.1038/sj.npp.1301029

[18] Mee-inta O, Zhao Z, Kuo Y. Physical Exercise Inhibits Inflammation and Microglial Activation. Cells. 2019 Jul 9;8(7):691. https://doi.org/https://doi.org/10.3390 /cells8070691

[19] Glascock J, Osman E, Coady T, Rose F, Shababi M, Lorson C. Delivery of Therapeutic Agents Through Intracerebroventricular (ICV) and Intravenous (IV) Injection in Mice. Journal of Visualized Experiments. 2011 Oct 3;(56):1-4. https://doi.org/10.3791/2968

[20] Kübra Elçioğlu, H., Kabasakal, L., Tufan, F., Elçioğlu, Ö., Solakoglu, S., Kotil, T. and Karan, M., 2015. Effects of systemic Thalidomide and intracerebroventricular Etanercept and Infliximab administration in a Streptozotocin induced dementia model in rats. Acta Histochemica, 117(2), pp.176-181.

[21] Gholizadeh, S., Tharmalingam, S., MacAldaz, M. and Hampson, D., 2013. Transduction of the Central Nervous System After Intracerebroventricular Injection of Adeno-Associated Viral Vectors in Neonatal and Juvenile Mice. Human Gene Therapy Methods. 2013 Aug 3;24(4):205-213. https://doi.org/10.1089/hgtb .2013 .076

[22] Rani S, Barbe M, Barr A, Litivn J. Role of TNF alpha and PLF in bone remodeling in a rat model of repetitive reaching and grasping. Journal of Cellular Physiology. 2010 Oct;225(1):152-167.https://doi.org/ 10.1002/jcp.22208

[23] Kara Y. The measurement of serum tumor necrosis factor-alpha levels in patients with lichen planus. Indian Journal of Dermatology. 2018 JulAug;63(4):297-300. https://doi.org/10.4103/ijd.IJD 474_17

[24]ELISA technical guide and protocols [Internet]. Tools.thermofisher.com. 2021 [cited 31 January 2021]. Available from: http://tools.thermofisher.com/ content/sfs/brochures/TR0065-ELISA-guide.pdf

[25] Chennaoui M, Gomez-Merino D, Drogou C, Geoffroy $\mathrm{H}$, Dispersyn G, Langrume C et al. Effects of exercise on brain and peripheral inflammatory biomarkers induced by total sleep deprivation in rats. Journal of Inflammation. 2015 Sep 30;12(1):1-10. https://doi.org/ $\underline{10.1186 / \mathrm{s} 12950-015-0102-3}$ 
UNDERGRADUATE RESEARCH IN NATURAL AND CLINICAL SCIENCE AND TECHNOLOGY (URNCST) JOURNAL

Read more URNCST Journal articles and submit your own today at: https://www.urncst.com

[26] QIAzol Lysis Reagent - QIAGEN Online Shop [Internet]. Qiagen. 2013 [cited 13 November 2020].

Available from: https://www.qiagen.com/ca/products/ discovery-and-translational-research/labessentials/buffers-reagents/qiazol-lysis-reagent/ \#orderinginformation

[27] Hernandez I, Sokolov B. Abnormal expression of serotonin transporter mRNA in the frontal and temporal cortex of schizophrenics. Molecular Psychiatry. 1997 Jan 1;2(1):57-64. https://doi.org/ $\underline{10.1038 / \text { sj.mp.4000215 }}$

[28] Khanzada F, Soomro N, Khan S. Association of Physical Exercise on Anxiety and Depression Amongst Adults [Internet]. 2015 [cited 31 January 2021]. Available from: http://doi.org/JCPSP, 25(7), 546-548.
[29] Morgan J, Olagunju A, Corrigan F, Baune B. Does ceasing exercise induce depressive symptoms? A systematic review of experimental trials including immunological and neurogenic markers. Journal of Affective Disorders. 2018;234:180-192.

[30] Winston, B., Lange-Carter, C., Gardner, A., Johnson, G. and Riches, D., 1995. Tumor necrosis factor alpha rapidly activates the mitogen-activated protein kinase (MAPK) cascade in a MAPK kinase kinase-dependent, c-Raf-1-independent fashion in mouse macrophages. Proceedings of the National Academy of Sciences.1995 Feb 28;92(5):1614-1618. https://doi.org/ 10.1073/pnas.92.5.1614

\section{Article Information}

Managing Editor: Jeremy Y. Ng

Peer Reviewers: Amy Yeung, Jordan Donders, Sonya Kouthouridis

Article Dates: Received Nov 02 20; Accepted Feb 20 21; Published Feb 2621

\section{Citation}

Please cite this article as follows:

Chen D, Lee S. The dynamic regulatory role of miR-132 in adult hippocampal neurogenesis and neural stem cell development. URNCST Journal. 2021 Feb 26: 5(2). https://urncst.com/index.php/urncst/article/view/211

DOI Link: https://doi.org/10.26685/urncst.211

\section{Copyright}

(C) David Chen, Seungmin Lee. (2021). Published first in the Undergraduate Research in Natural and Clinical Science and Technology (URNCST) Journal. This is an open access article distributed under the terms of the Creative Commons Attribution License (https://creativecommons.org/licenses/by/4.0/), which permits unrestricted use, distribution, and reproduction in any medium, provided the original work, first published in the Undergraduate Research in Natural and Clinical Science and Technology (URNCST) Journal, is properly cited. The complete bibliographic information, a link to the original publication on http://www.urncst.com, as well as this copyright and license information must be included.

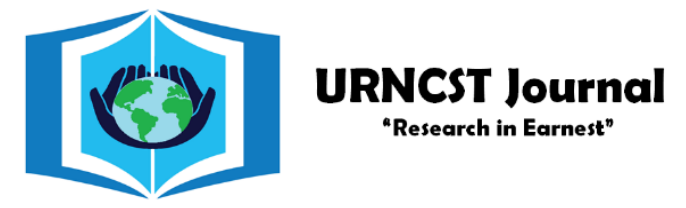

\section{Funded by the Government of Canada}

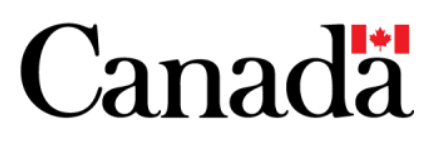

Do you research in earnest? Submit your next undergraduate research article to the URNCST Journal!

| Open Access | Peer-Reviewed | Rapid Turnaround Time | International |

| Broad and Multidisciplinary | Indexed | Innovative | Social Media Promoted |

Pre-submission inquiries? Send us an email at info@ urncst.com | Facebook, Twitter and LinkedIn: @ URNCST

Submit YOUR manuscript today at https://www.urncst.com! 